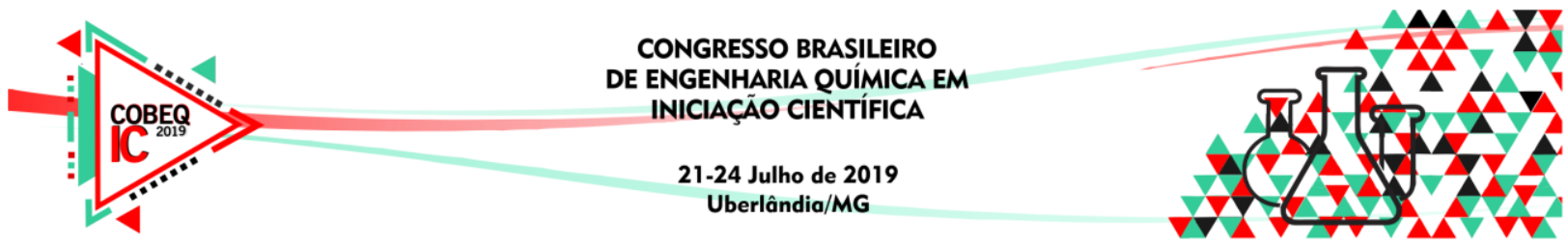

\title{
HIDRÓLISE ÁCIDA COM SORGO GRANÍFERO
}

\author{
W. A. DIAS ${ }^{1}$, L. F. MILANI ${ }^{1}$, L. C. FERREIRA ${ }^{1}$ e U. C. FILHO $^{1}$ \\ ${ }^{1}$ Universidade Federal de Uberlândia, Faculdade de Engenharia Química \\ E-mail para contato: warlendias962@gmail.com, laurafmilani@gmail.com, \\ laysecaixetaeq@gmail.com,ucfilho@gmail.com
}

\begin{abstract}
RESUMO - O cultivo de sorgo tornou-se uma atividade amplamente praticada no Brasil, mais notadamente na região Nordeste, por meio dos escravos africanos que trabalhavam na atividade açucareira (Ribas, 2003). No presente, essa prática concretizou-se como uma importante alternativa no mercado de energia renovável por intermédio da produção de etanol a partir desse grão, devido ao seu alto potencial energético. Embora no Brasil a produção de etanol seja predominantemente por meio da sacarose (Rodríguez-Zúñiga et al., 2011), a produção a partir do amido tem-se tornado atraente para as usinas produtoras de etanol, isso porque o sorgo cresce durante o período de entressafra da cana de açúcar. Dessa forma, para obter o etanol a partir do sorgo, a hidrólise é uma etapa que se destaca pela quebra do amido em glicose e outros açúcares redutores. Sendo assim, este estudo buscou avaliar o processo de hidrólise ácida empregando três tipos de ácidos: $\mathrm{HCl}$ (ácido clorídrico), $\mathrm{H}_{2} \mathrm{SO}_{4}$ (ácido sulfúrico) e $\mathrm{H}_{3} \mathrm{PO}_{4}$ (ácido fosfórico), nas concentrações de $0,5 \%, 1 \%$ e $2 \%$. A melhor condição de hidrólise ácida do sorgo foi obtida no tempo de 25 min e concentração de $1 \%$ de $\mathrm{HCl}$, obtendo-se no meio hidrolisado $14,94 \mathrm{~g} / \mathrm{L}$ de glicose.
\end{abstract}

\section{INTRODUÇÃO}

A busca por fontes renováveis de energia que reduzem os impactos no ambiente temse tornado cada vez mais necessária. Por essa razão, a produção de bioetanol no Brasil destacou-se por utilizar a cana-de-açúcar como principal fonte para a geração do biocombustível (Masson et al., 2013). Entretanto, no período de entressafra da cana-de-açúcar (dezembro a março), o valor do etanol torna-se mais oneroso, uma vez que, as usinas ficam paradas para a manutenção das plantas industriais. É nesse contexto que surge biomassas alternativas como sorgo. Esse composto é rico em amido e possui baixo custo de produção que se expandiu no século passado em várias regiões do mundo.

O sorgo (Sorghum bicolor, L. Moench) é uma planta originária da África introduzido no Brasil pelo Nordeste, por meio dos escravos africanos que trabalhavam na atividade açucareira (Ribas, 2003). Atualmente é o quinto cereal mais plantado no mundo, atrás do trigo, arroz, milho e da cevada (May et al., 2011).

Popularmente integrado na ração animal, o sorgo passou a ser visto como potencial aliado da cana-de-açúcar. É sabido que perduram-se cerca de 110 dias (safrinha), desde seu plantio até a colheita, podendo então ser cultivado nos períodos de entressafra da cana, promovendo uma continuidade no trabalho da usina, até mesmo porque os maquinários 


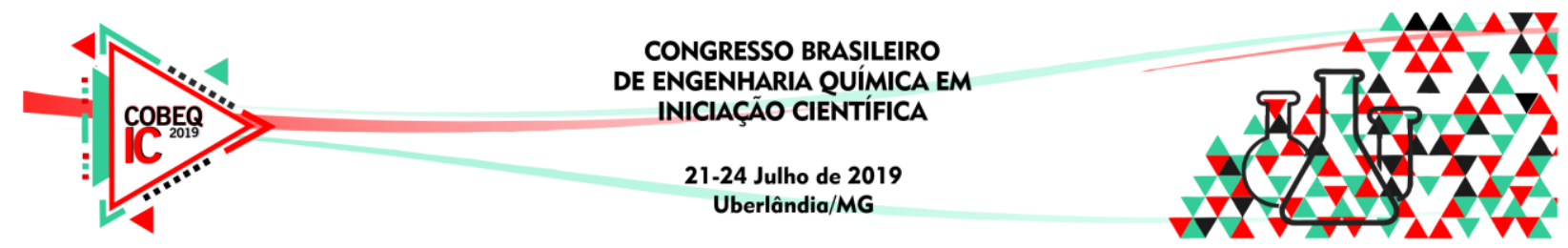

utilizados são semelhantes, necessitando-se apenas de poucas modificações (Landau et al., 2015).

Existem basicamente quatro variedades de sorgo: granífero, forrageiro, sacarino e vassoura. No presente trabalho foi utilizado o sorgo granífero que possui como algumas características: resistência ao estresse hídrico; porte baixo (colheita com maquinários tradicionais); grãos pesados e tolerantes a deterioração; secagem rápida, entre outros.

Na obtenção do etanol a partir do sorgo, tem-se uma importante etapa: a hidrólise, que pode ser ácida ou enzimática. A hidrólise ácida é uma reação química em meio aquoso (diluído ou concentrado), onde a água liberará seu cátion $\left(\mathrm{H}^{+}\right)$e seu ânion $\left(\mathrm{OH}^{-}\right)$. Seus íons, então, se associarão ao ácido em questão presente na solução formando assim os produtos desejados (Hijazin et al., 2010). A hidrólise proporcionará que os diferentes tipos de açúcares presentes na solução sejam liberados para posterior fermentação alcoólica.

Dessa forma, o presente trabalho buscou avaliar o processo de hidrólise ácida empregando três tipos de ácidos para a análise de melhor rendimento e qualidade: $\mathrm{HCl}$ (ácido clorídrico), $\mathrm{H}_{2} \mathrm{SO}_{4}$ (ácido sulfúrico) e $\mathrm{H}_{3} \mathrm{PO}_{4}$ (ácido fosfórico), nas concentrações de 0,5\%, $1 \%$ e $2 \%$.

\section{MATERIAL E MÉTODOS}

Neste trabalho, o sorgo granífero estudado foi fornecido pela Empresa Brasileira de Pesquisa Agropecuária (Embrapa) e todos os ensaios foram realizados nos laboratórios do Núcleo de Processos Biotecnológicos (NUCBIO) da Faculdade de Engenharia Química (FEQUI), da Universidade Federal de Uberlândia (UFU). A hidrólise ácida foi realizada com o intuito de obter açúcares orgânicos por meio do rompimento das moléculas do sorgo através do fornecimento de íons $\mathrm{H}_{3} \mathrm{O}^{+}$(hidroxônio) como cátions, em solução aquosa (Politi, 1982). Os ácidos utilizados nessa reação hidrolítica foram o ácido sulfúrico $\left(\mathrm{H}_{2} \mathrm{SO}_{4}\right)$, o ácido clorídrico $(\mathrm{HCl})$ e o ácido fosfórico $\left(\mathrm{H}_{3} \mathrm{PO}_{4}\right)$ em diferentes concentrações $(0,5 \%, 1 \%$ e $2 \%)$.

Inicialmente, foi efetuado o preparo da solução ácida e, na sequência, a mesma foi adicionada em um erlenmeyer de $250 \mathrm{~mL}$ juntamente com $3 \mathrm{~g}$ de sorgo. Após a autoclavagem a $120^{\circ} \mathrm{C}$, a solução foi neutralizada por $\mathrm{CaCO}_{3}$ até atingir o $\mathrm{pH}$ próximo de $4,5 \mathrm{e}$, em seguida, centrifugada a $7000 \mathrm{rpm}$ por 20 minutos para remover a parte sólida. A autoclavagem foi realizada em duas condições considerando tempos diferentes, sendo 50 minutos e 25 minutos.

Após a hidrólise, as amostras foram centrifugadas e filtradas. Na sequência, foram retiradas alíquotas para a quantificação dos açúcares: sacarose e glicose. A análise foi realizada por HPLC, marca Shimadzu modelo LC-20A Prominence, coluna SUPELCOGEL C-610H.

\section{RESULTADOS E DISCUSSÃO}

$\mathrm{Na}$ análise realizada no HPLC foi possível identificar os açúcares redutores gerados pela hidrólise ácida: sacarose e glicose. Segundo Gomes (2011), o sorgo sacarino possui maior teor de açúcares redutores em comparação com caldo de cana, sendo que os principais açúcares livres no caldo de sorgo sacarino são: glicose, sacarose e frutose, compatíveis com 


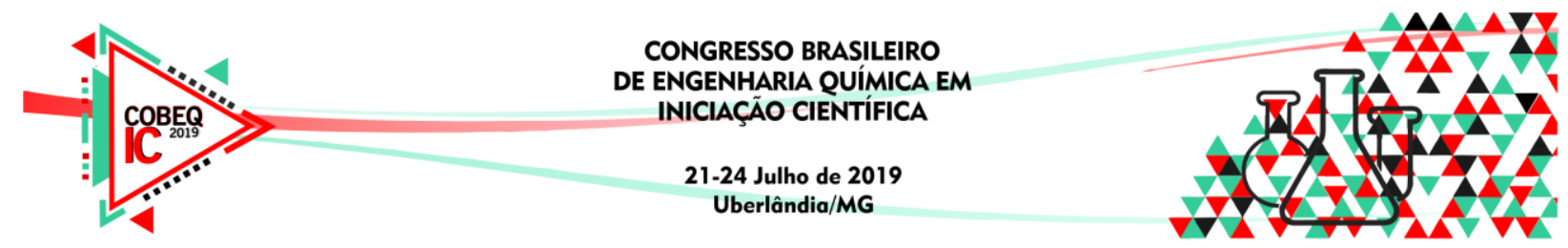

os encontrados no presente estudo. Os dados da concentração de sacarose nos tempos de 25 e 50 minutos, respectivamente, encontram-se na Figura 1.

Analisando os dados da Figura 1 foi possível observar que 3,21 g/L de sacarose foi obtida na condição de ácido sulfúrico $1 \%$ em 25 minutos de hidrólise. Este valor é menor quando comparado ao produzido pelos sorgos sacarinos que possuem uma grande quantidade de sacarose. No entanto, o ácido sulfúrico apresentou resultados satisfatórios no tempo de 50 minutos de hidrólise, sendo produzidos $1,87 \mathrm{~g} / \mathrm{L}$ de sacarose e 12,21 g/L de glicose nas condições de $1 \%$ e $2 \%$, respectivamente. Observa-se que utilizando esse ácido, um tempo maior é necessário para que as moléculas sejam quebradas durante sua hidrólise.

Figura 1 - Gráfico de concentração de sacarose no tempo de 25 (A) e 50 (B) minutos

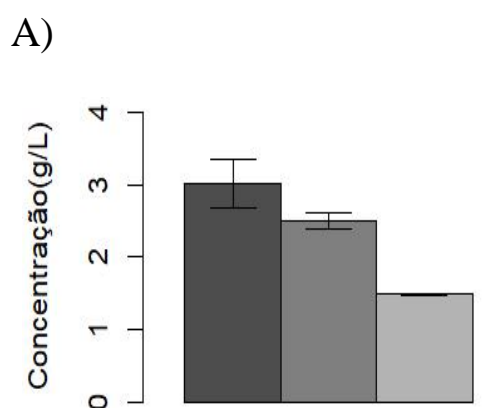

$\mathrm{HCl}$

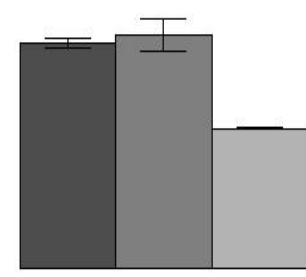

$\mathrm{H} 2 \mathrm{SO} 4$

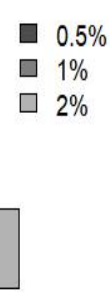

B)

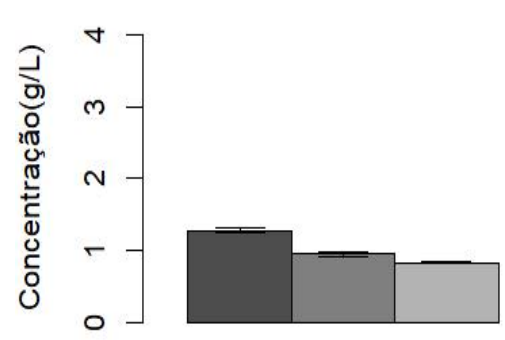

$\mathrm{HCl}$

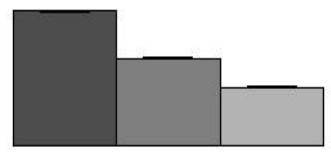

$\mathrm{H} 2 \mathrm{SO} 4$
$\mathrm{H} 3 \mathrm{PO} 04$

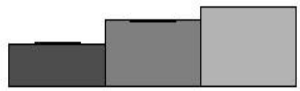

Na Figura 2 estão dispostos os dados de concentração de glicose em ambos os tempos estudados. Diferentemente dos ácidos sulfúrico e fosfórico, o ácido clorídrico apresentou uma concentração maior nas condições avaliadas devido a força maior do ácido em quebrar as moléculas em açúcares redutores. Assim, foi observado que a maior concentração de glicose ocorreu na condição de ácido clorídrico 1\% em 25 minutos de hidrólise, com o valor de 14,94 $\mathrm{g} / \mathrm{L}$. 


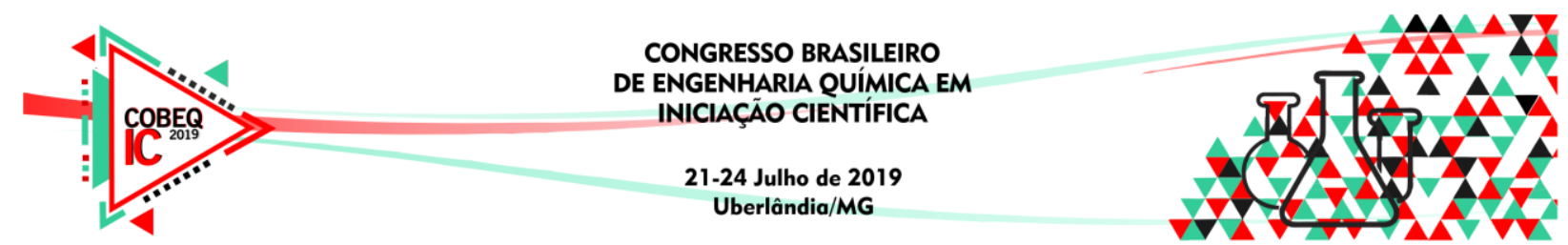

Figura 2 - Gráfico de concentração de glicose no tempo de 25 (C) e 50 (D) minutos

C)

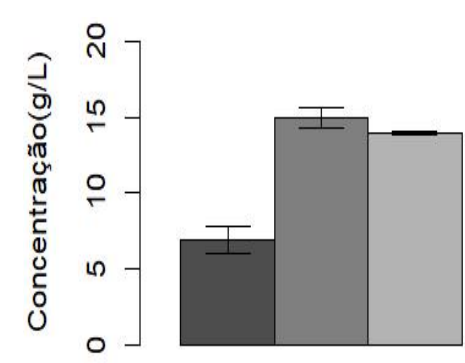

$\mathrm{HCl}$

D)

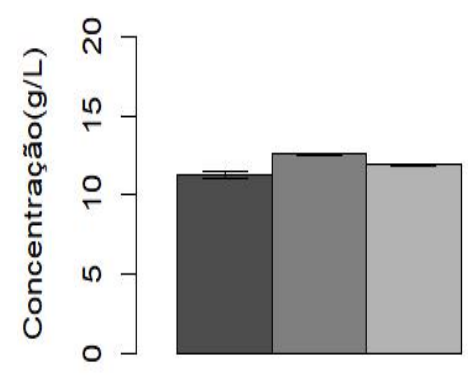

$\mathrm{HCl}$

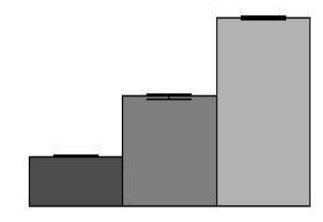

$\mathrm{H} 2 \mathrm{SO} 4$

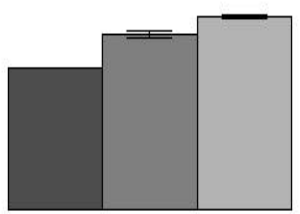

$\mathrm{H} 2 \mathrm{SO} 4$

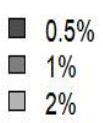

$1 \%$

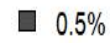

$\square \quad 1 \%$

$\square 2 \%$

De acordo com Montes (2017), durante o processo de fermentação alcoólica o melhor microrganismo para tal etapa é a levedura Sacharomyces cerevisiae. Isso porque essa levedura apresenta melhores desempenhos em relação à produtividade e tolerância alcóolica, além de ser responsável por converter glicose em etanol. Sendo assim, visando um melhor rendimento na etapa fermentativa da produção de etanol deve-se optar pelo ácido que resulta a maior concentração de glicose no processo de hidrólise. Nesse caso, o ácido clorídrico $1 \%$ no tempo de 25 minutos foi destacado com a maior concentração de glicose, o que trata-se de uma alternativa viável pois, além de ser mais barato, o ácido clorídrico possui menor poder oxidante/corrosivo em relação ao ácido sulfúrico (Pediaa, 2019).

\section{CONCLUSÃO}

Verificou-se que dentre os ácidos estudados (ácido clorídrico, ácido sulfúrico, ácido fosfórico), foram obtidos resultados satisfatórios para o ácido clorídrico, que apresentou maiores concentrações de sacarose e glicose no tempo de 25 minutos de hidrólise, o que tratase de uma alternativa viável para a hidrólise ácida uma vez que o ácido clorídrico possui poder oxidante/corrosivo menor que o ácido sulfúrico. Pode-se concluir também que o tempo de 25 minutos foi melhor que o tempo de 50 minutos, obtendo-se $3,21 \mathrm{~g} / \mathrm{L}$ de sacarose e 14,5 $\mathrm{g} / \mathrm{L}$ de glicose. 


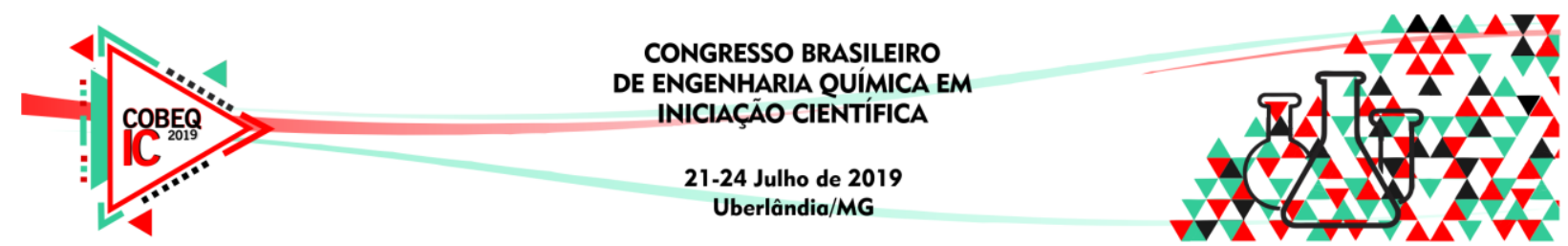

\section{REFERÊNCIAS}

GOMES, A.; RODRIGUES, D.; OLIVEIRA, P., Sorgo sacarino: tecnologia agronômica e industrial para alimentos e energia. Revista de Agroenergia, v. 3, p. 26, 2011.

HIJAZIN, C. A. H.; SIMÕES, A. T.; SILVEIRA, D. R. Hidrólise ácida, alcalina e enzimática, 2010

LANDAU, E. C.; NETTO, D. A. M. Boletim de Pesquisa e Desenvolvimento 125: Expansão Potencial da Produção de Sorgo Granífero no Brasil no Sistema de Rotação com Soja Considerando o Zoneamento de Risco Climático, 2015/16.

MASSON, I. S.; MUTTON, M. J. R. Produção de bioetanol a partir da fermentação de caldo de sorgo sacarino e cana de açúcar, 2013.

MAY, A.; MAGALHÃES, P.C.; ABREU, M.C.; PARRELLA, N.N.L.D.; CAMPANHA, M.M.; SILVA, A.F.; SCHAFFERT, R.E.; PARRELLA, R.A. da C. Fito-hormônios no desenvolvimento vegetativo e germinação das sementes de sorgo sacarino. Revista Brasileira de Milho e Sorgo, v.12, n.1, p.33-43, 2013.

MONTES, A. C. R. Avaliação do processo de obtenção de etanol de $2^{a}$ geração utilizando bagaço de cana. Monografia de graduação, p. 25. 2017.

PEDIAA. "Difference Between Hydrochloric Acid and Sulfuric Acid". Disponível em:< https://pediaa.com/difference-between-hydrochloric-acid-and-sulfuric-acid/ > . Acessado em 4 de maio de 2019.

POLITI, Elie. Química. 3. edição São Paulo: Moderna, 1982.

RIBAS, P. M. Sorgo: introdução e importância. Embrapa Milho e Sorgo, Documentos 26, $16 p, 2003$.

RODRÍGUEZ-ZÚÑIGA, U. F.; FARINAS, C. S; NETO, V. B.; COURI, S.; CRESTANA, S. Produção de celulases por Aspergillus niger por fermentação em estado sólido, 2011. 